\title{
Ankle Joint
}

National Cancer Institute

\section{Source}

National Cancer Institute. Ankle Joint. NCI Thesaurus. Code C32078.

A gliding joint between the distal ends of the tibia and fibula and the proximal end of the talus. 